\title{
Unbalanced oxidant-induced DNA damage and repair in COPD: a link towards lung cancer
}

\author{
Gaetano Caramori, ${ }^{1}$ lan M Adcock, ${ }^{2}$ Paolo Casolari, ${ }^{1}$ Kazuhiro Ito, ${ }^{2}$ Elen Jazrawi, ${ }^{2}$ \\ Loukia Tsaprouni, ${ }^{2}$ Gino Villetti, ${ }^{3}$ Maurizio Civelli, ${ }^{3}$ Chiara Carnini, ${ }^{3}$ Kian Fan Chung, ${ }^{2}$ \\ Peter J Barnes, ${ }^{2}$ Alberto Papi ${ }^{1}$
}

- An additional table is published online only. To view this file please visit the journa online (http://thorax.bmj.com).

${ }^{1}$ Centro di Ricerca su Asma e BPCO University of Ferrara, Ferrara, Italy

${ }^{2}$ Airway Disease Section, Imperial College London, UK ${ }^{3}$ Department of Pharmacology, Chiesi Farmaceutici, Parma, Italy

\section{Correspondence to}

Gaetano Caramori, Centro di

Ricerca su Asma e BPCO,

University of Ferrara, Via

Savonarola, 9, Ferrara 44100,

Italy; gaetano.caramori@unife.it

Gaetano Caramori, lan M

Adcock, Peter J Barnes and

Alberto Papi have contributed

equally to this work.

Received 29 November 2010 Accepted 24 February 2011

Published Online First

2 April 2011

\begin{abstract}
Background Chronic obstructive pulmonary disease

(COPD) is characterised by oxidative stress and

increased risk of lung carcinoma. Oxidative stress causes

DNA damage which can be repaired by DNA-dependent protein kinase complex.

Objectives To investigate DNA damage/repair balance and DNA-dependent protein kinase complex in COPD lung and in an animal model of smoking-induced lung damage and to evaluate the effects of oxidative stress on Ku expression and function in human bronchial epithelial cells.
\end{abstract}

Methods Protein expression was quantified using immunohistochemistry and/or western blotting. DNA damage/repair was measured using colorimetric assays. Results $8-\mathrm{OH}-\mathrm{dG}$, a marker of oxidant-induced DNA damage, was statistically significantly increased in the peripheral lung of smokers (with and without COPD) compared with non-smokers, while the number of apurinic/apyrimidinic (AP) sites (DNA damage and repair) was increased in smokers compared with non-smokers $(p=0.0012)$ and patients with COPD $(p<0.0148)$. Nuclear expression of Ku86, but not of DNA-PKcs, phospho-DNA-PKcs, Ku70 or $\gamma$-H2AFX, was reduced in bronchiolar epithelial cells from patients with COPD compared with normal smokers and non-smokers $(p<0.039)$. Loss of Ku86 expression was also observed in a smoking mouse model $(p<0.012)$ and prevented by antioxidants. Oxidants reduced $(p<0.0112)$ Ku86 expression in human bronchial epithelial cells and Ku86 knock down modified AP sites in response to oxidative stress.

Conclusions Ineffective DNA repair rather than strand breakage per se accounts for the reduced AP sites observed in COPD and this is correlated with a selective decrease of the expression of Ku86 in the bronchiolar epithelium. DNA damage/repair imbalance may contribute to increased risk of lung carcinoma in COPD.

\section{INTRODUCTION}

Lung cancer remains a major worldwide health problem, accounting for more than a sixth of cancer deaths. The incidence of lung cancer is highest in the more developed countries of North America and northern Europe. In these regions, more than $90 \%$ of cases in men and $80 \%$ of cases in women are related to smoking. ${ }^{1}$

Cigarette smoking is also the most important risk factor for chronic obstructive pulmonary disease (COPD). ${ }^{2}$ Thus, lung carcinoma and COPD share a common risk factor, tobacco smoking,

\section{Key messages}

What is the key question?

- Is the balance between DNA damage and repair altered in COPD lung?

What is the bottom line?

- In COPD lung there is an unbalanced oxidantinduced DNA damage and repair correlated with a selective decrease of the expression of Ku86 in the bronchiolar epithelium.

\section{Why read on?}

- Because it provides a molecular mechanism to explain the increased risk of lung cancer in patients with COPD, in addition to their smoking habit.

through which they also possibly share similar pathogenetic mechanisms that are still largely unknown at the molecular level.

Furthermore, COPD is an independent risk factor for lung carcinoma among smokers; increasing the risk of lung cancer twofold, with the risk increasing with COPD severity. ${ }^{3-5}$

COPD is also associated with increased oxidative stress in the lower airways which can cause DNA damage and lung carcinogenesis. ${ }^{6}$ Damage to DNA induces several cellular responses that enable cells either to eliminate or cope with the damage or to activate programmed cell death, thereby eliminating cells with potentially harmful mutations. ${ }^{7}$

DNA repair mechanisms include direct repair, base excision repair, nucleotide excision repair, double-strand break (DSB) repair, and cross-link repair. ${ }^{7}$ Efficient repair of DNA DSBs is essential for the maintenance of chromosomal integrity. ${ }^{8}$ DSBs are repaired either by homologous recombination or by non-homologous end-joining (NHEJ) with the latter being the primary pathway involved. ${ }^{8} 9$ Six distinct proteins function in the NHEJ pathway (Ku70, Ku86, XRCC4, DNA ligase IV, Artemis, DNA-PKcs). ${ }^{89}$

The heterotrimeric DNA-dependent protein kinase (DNA-PK) complex is a serine-threonine kinase activated by the presence of DSBs in DNA and composed of a catalytic subunit (DNAPKcs) and the DNA-binding heterodimer of the regulatory subunits $\mathrm{Ku}$ proteins (Ku70 and Ku86). Autophosphorylation of DNA-PKcs (phosphoDNA-PKcs (pS2612)) correlates with loss of protein 
kinase activity and dissociation of the DNA-PKcs-Ku complex. DNA-PK is localised in the nucleus and it is critical during NHEJ because it initially recognises and binds to the damaged DNA and then targets the other repair activities to the site of DNA damage. ${ }^{8-10}$

In addition to the regulatory function of the $\mathrm{Ku}$ proteins in DNA-PK, heterodimers of both Ku70 and Ku86 also have independent DNA repair functions. ${ }^{8-10}$ It has been documented in vitro that oxidative stress can induce nuclear loss of $\mathrm{Ku}$ proteins in pancreatic epithelial cells. ${ }^{11}$

Apurinic/apyrimidinic (AP) sites are common lesions in DNA and are formed either spontaneously or as intermediates during the course of base excision repair of oxidised, deaminated and alkylated bases. ${ }^{12}$ It has been estimated that about $2 \times 10^{5}$ base lesions are generated per cell per day. The level of AP sites in cells is thought to be a good indicator of both ongoing DNA damage and repair induced by chemical agents and cell ageing. ${ }^{12}$

8-Hydroxy-2-deoxyguanosine (8-OH-dG) is produced by the oxidative damage of DNA by reactive oxygen and nitrogen species and serves as an established marker of oxidative stress. ${ }^{13}$ $8-\mathrm{OH}-\mathrm{dG}$ is increased in the peripheral lung of patients with pulmonary emphysema. ${ }^{14}$ After a DNA DSB a variant histone $\mathrm{H} 2 \mathrm{~A}$, termed H2A.x (which replaces conventional $\mathrm{H} 2 \mathrm{~A}$ in a subset of nucleosomes), is rapidly phosphorylated at Serine 139 by ATM kinase. Phospho-S139-H2A.x is also known as $\gamma$-H2AFX. ${ }^{15}$ This phosphorylation step can extend up to several thousand nucleosomes from the actual site of the DSB and may mark the surrounding chromatin for recruitment of proteins required for DNA damage signalling and repair. ${ }^{15}$ Both $8-O H-d G$ and $\gamma$-H2AFX are considered sensors of oxidative stress-induced DNA damage.

The aim of this study was to investigate the degree of oxidant-induced DNA damage and DNA repair and the localisation and expression of DNA-PKcs, DNA-PKcs (pS2612), Ku70, Ku86 and $\gamma$-H2AFX in lung parenchyma of patients with COPD compared with smokers with normal lung function and nonsmokers (control groups). The study also analysed the effects of oxidative stress on $\mathrm{Ku}$ protein expression in primary human bronchial epithelial cells in vitro, the functional effect of Ku86 knockdown in bronchial epithelial cells and the effect of cigarette smoke exposure on bronchial epithelial cell Ku86 expression in an animal model in vivo.

\section{METHODS}

\section{Participants}

We recruited a total of 69 patients (64 undergoing lung resection for a solitary peripheral carcinoma (11 non-smokers, 28 smokers with normal lung function and 25 with COPD) and five nonsmokers undergoing lung transplantation). All patients were recruited from the Respiratory Diseases Clinic of the University Hospital of Ferrara, Italy and from the Royal Brompton Hospital, Imperial College London, UK.
For the DNA damage/repair and DNA fragility studies, 11 were smokers with COPD, 15 were smokers with normal lung function and seven were non-smokers (table 1). Samples from 14 smokers with COPD, 13 smokers with normal lung function and nine non-smokers were used for immunohistochemical and western blotting studies (table 2). COPD was defined according to international guidelines. ${ }^{2}$ All patients were stable at the time of the study and were free from acute exacerbations of symptoms and from upper respiratory tract infections in the 2 months preceding the study. None had received glucocorticoids, theophylline, antibiotics or antioxidants within the month preceding surgery or bronchodilators within the previous $48 \mathrm{~h}$. Patients had no history of asthma or other allergic diseases. Former smokers had stopped smoking for more than 1 year. Each patient underwent medical history, physical examination, chest radiography, electrocardiogram, routine blood tests, and pulmonary function tests during the week prior to surgery. The study was approved by the ethics committees of the University Hospital of Ferrara and the Royal Brompton Hospital.

Pulmonary function tests were performed as previously described ${ }^{16}$ according to published guidelines. ${ }^{17}$ Predicted values for the different measures were calculated from the regression equations published by Quanjer and colleagues. ${ }^{17}$

\section{Experimental methods}

The cigarette smoke-exposed mouse model, the immunohistochemistry in human and mouse lungs for DNA-PKcs, DNA-PKcs (pS2612), Ku70, Ku86 and $\gamma$-H2AFX, the DNA damage/repair quantification and DNA fragility assays, the western blot analysis for Ku70 and Ku86 in human lung parenchyma, the culture of primary human bronchial epithelial cells and the Ku86 knockdown siRNA in human bronchial epithelial cells are all described in full detail in the online data repository.

\section{Statistical analysis}

Group data were expressed as mean and SD or median (25-75 percentiles), as appropriate. Analysis of variance for clinical data and the Kruskal-Wallis test for histological data were used to determine differences between groups. The Mann-Whitney $U$ test was performed after the Kruskal-Wallis test when appropriate. Bonferroni adjustment was applied when indicated. Categorical values were compared by means of the $\chi^{2}$ test. A probability value of $<0.05$ was considered statistically significant.

\section{RESULTS}

\section{Clinical data}

Tables 1 and 2 show the characteristics of the patients recruited. There was no significant difference in the smoking history between patients with COPD and smokers with normal lung function $(p=0.8279$ and $p=0.5369$ for pack-years of COPD vs smokers in tables 1 and 2). The prevalence of chronic bronchitis

Table 1 Characteristics of participants taking part in the DNA damage/repair and DNA fragility studies

\begin{tabular}{lrlllllll}
\hline Participants & N & Age & Sex & $\begin{array}{l}\text { Smoking } \\
\text { history }\end{array}$ & Pack-years & $\begin{array}{l}\text { Chronic } \\
\text { bronchitis }\end{array}$ & FEV $_{\mathbf{1}} \%$ pred & FEV $/ \mathbf{F V C} \%_{1}$ \\
\hline Non-smokers & 7 & $51.6(17.5)$ & $3 \mathrm{M} / 4 \mathrm{~F}$ & All never & 0 & 0 & $\mathrm{ND}$ & $\mathrm{ND}$ \\
Smokers & 15 & $69.5(5.5)$ & $13 \mathrm{M} / 2 \mathrm{~F}$ & $\begin{array}{l}6 \mathrm{ex}, \\
5 \mathrm{current}\end{array}$ & $48.9(28.6)$ & 9 & $94.6(19.9)$ & $75.4(4)$ \\
COPD & 11 & $69(6.7)$ & $11 \mathrm{M}$ & $\begin{array}{l}5 \mathrm{ex}, \\
4 \mathrm{current}\end{array}$ & $43.6(26.6)$ & 4 & $77.7(15.6)$ & $64(1.4)$ \\
\hline
\end{tabular}

For patients with chronic obstructive pulmonary disease (COPD) and smokers with normal lung function predicted forced expiratory volume in $1 \mathrm{~s}$ ( $\mathrm{FEV}_{1} \%$ pred) and $\mathrm{FEV}_{1} /$ forced vital capacity (FVC)\% are post-bronchodilator values.

$\mathrm{ND}$, not done in five participants; two had a $\mathrm{FEV}_{1} / \mathrm{FVC}$ ratio of $77(5.6) \%$ of predicted.

$M$, male; F, female. Data expressed as mean (SD). 
Table 2 Characteristics of participants taking part in the immunohistochemistry and western blotting studies

\begin{tabular}{|c|c|c|c|c|c|c|c|c|}
\hline Participants & $\mathbf{n}$ & Age & Sex & $\begin{array}{l}\text { Smoking } \\
\text { history }\end{array}$ & Pack-years & $\begin{array}{l}\text { Chronic } \\
\text { bronchitis }\end{array}$ & $\mathrm{FEV}_{1} \%$ pred & $\mathrm{FEV}_{1} / \mathrm{FVC} \%$ \\
\hline Non-smokers & 9 & $71.2(9.7)$ & $3 \mathrm{M} / 6 \mathrm{~F}$ & All never & 0 & 0 & $111.1(16.4)$ & $84.6(6.7)$ \\
\hline Smokers & 13 & $68.7(7.5)$ & $11 \mathrm{M} / 2 \mathrm{~F}$ & $\begin{array}{l}6 \text { ex, } \\
5 \text { current }\end{array}$ & $33.7(20)$ & 5 & $96.7(19.6)$ & $77.6(4.5)$ \\
\hline COPD & 14 & $70.9(4.1)$ & $11 \mathrm{M}$ & $\begin{array}{l}5 \text { ex, } \\
4 \text { current }\end{array}$ & $37.7(23.8)$ & 9 & $70.2(16.2)$ & $61(7.8)$ \\
\hline
\end{tabular}

For chronic obstructive pulmonary disease (COPD) and smokers with normal lung function predicted forced expiratory volume in $1 \mathrm{~s}$

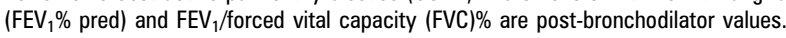

$\mathrm{M}$, male; F, female. Data expressed as mean (SD).

was $52 \%$ in the COPD group and $50 \%$ in the smokers with normal lung function.

\section{DNA damage/repair in lung parenchyma}

DNA samples from patients with COPD were more fragile and liable to degradation than those obtained from non-smokers and smokers with normal lung function (figure 1A). In order to explain this we examined markers of specific DNA damage and repair. The degree of oxidative stress-induced DNA damage was similar in healthy smokers and smokers with COPD as determined by the level of $8-\mathrm{OH}-\mathrm{dG} / \mu \mathrm{g}$ DNA (figure $1 \mathrm{~B}$ ) and statistically significantly greater than that observed in normal controls $(0.26(0.17)$ and 0.29 (0.17) vs 0.06 $(0.04)$ respectively; $p=0.0033)$. However, the number of AP sites, a marker of DNA damage and repair, was elevated in smokers with normal lung function (2.863 (1.31)) compared with healthy non-smokers (1.195 (0.33); $\mathrm{p}=0.0012)$ and patients with COPD (1.607 (0.73); $p=0.0148)$. The number of AP sites in patients with COPD, however, was not statistically significantly different compared with non-smokers $(p=0.2048)$ (figure 1C). The current smoking status had no effect on AP sites.

\section{Immunohistochemistry for DNA-PKcs, DNA-PKcs (pS2612), Ku70, Ku86 and $\gamma$-H2AFX in human lung parenchyma}

The authors postulated that there may be decreased DNA repair in $\mathrm{COPD}$, therefore components of this process were analysed.
Ku86 was mainly localised to the nucleus in both structural and inflammatory cells of the lungs (figure 2). The number of bronchiolar epithelial cells without nuclei positively stained for Ku86 was statistically significantly higher in patients with COPD (median (IOR) 3.54\% (1.85-5.75), $\mathrm{n}=14$ ), but not in healthy smokers $(1.5 \%(0.3-5.4), \mathrm{n}=13)$, compared with non-smokers $(1 \%(0.6-1.8), \mathrm{n}=9) \quad(\mathrm{p}<0.039)$. In addition, the amount of Ku86 protein $(0.26(0.04)$ vs $0.4(0.03) \mathrm{Ku} 86 /$ actin ratio $\mathrm{OD}$ arbitrary units; $\mathrm{p}=0.026)$, but not total $\mathrm{Ku} 70(0.49$ (0.14) vs $0.45(0.1) ; p=0.82)$ in lung parenchyma demonstrated a statistically significantly decrease in COPD $(n=6)$ compared with smokers with normal lung function $(n=6)$ (figure $2 \mathrm{D}$ ).

DNA-PKcs, DNA-PKcs (pS2612), Ku70 and $\gamma$-H2AFX were localised exclusively in the nucleus in all cells, including bronchiolar epithelial cells (all bronchiolar epithelial cells were stained in all three groups). There was no statistically significant difference in their localisation and global expression among the three groups for DNA-PKcs and Ku70 (figures 3 and 4 and online table S1) and between smokers with normal lung function and patients with COPD for DNA-PKcs (pS2612) and $\gamma$-H2AFX (figures 3 and 4 and online table S1).

Furthermore, no statistically significant differences in the percentage of endoalveolar macrophages stained for DNA-PKcs, $\mathrm{Ku} 70$, and Ku86 among the three groups and between smokers with normal lung function and patients with COPD for DNA-PKcs (pS2612) and $\gamma$-H2AFX were seen (all endoalveolar macrophages were stained in all three groups).
Figure 1 (A) Ethidium bromide staining of freeze-thawed DNA extracted from nonsmokers $(n=6)$, smokers with normal lung function $(n=6)$ and patients with mild to moderate COPD $(n=10)$. (B) Graphical representation of 8-hydroxy-2deoxyGuanosine $(8-\mathrm{OH}-\mathrm{dG})$ content, an index of oxidative stress-induced DNA damage, in human lung parenchyma obtained from nonsmokers $(n=7)$, healthy smokers with normal lung function $(n=15)$ and patients with COPD $(n=11)$. Histograms represent mean (SD). (C) Graphical representation of AP sites, indexes of DNA damage and repair, in human lung parenchyma obtained from non-smokers $(n=7)$, healthy smokers with normal lung function $(n=15)$ and patients with COPD $(n=11)$. Histograms represent mean (SD).

A

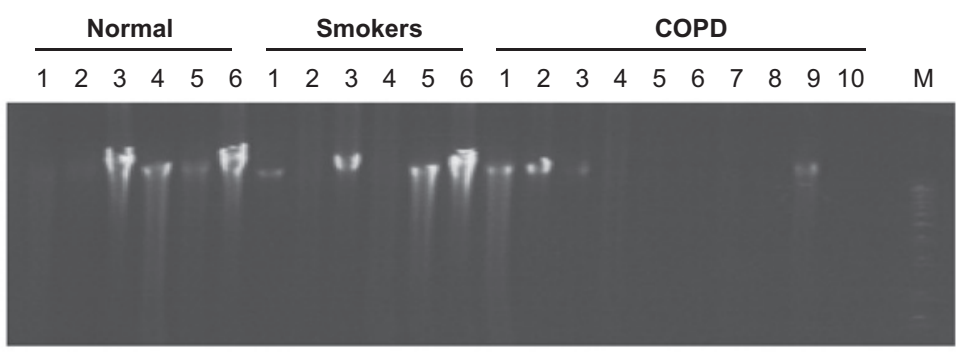

B

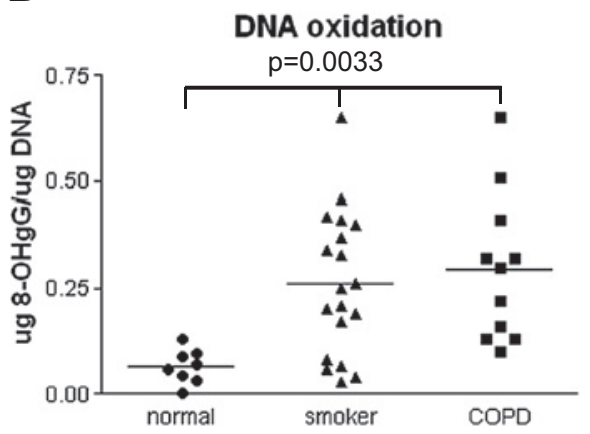

C

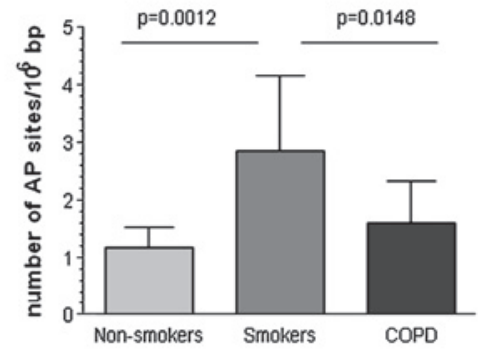




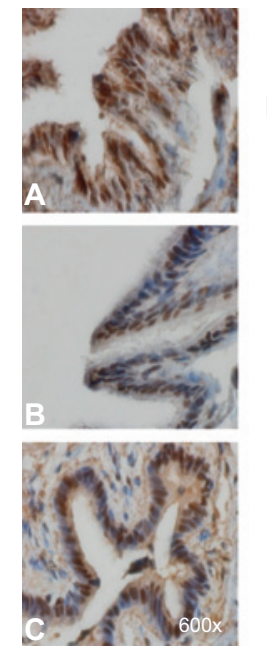

\section{D}
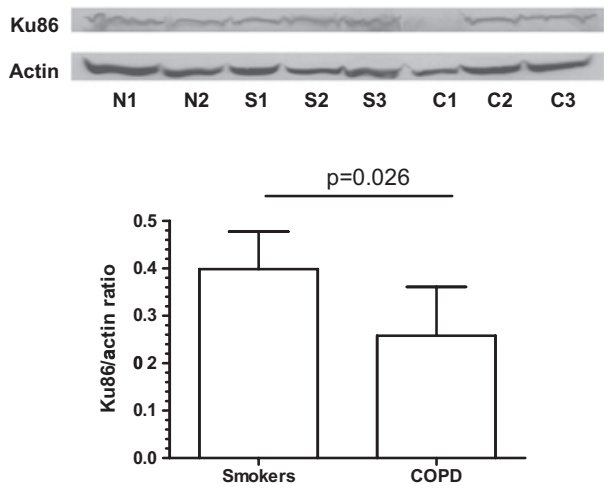

Figure 2 Photomicrographs showing the bronchiolar epithelium from a non-smoker $(A)$, a healthy smoker with normal lung function $(B)$ and a patient with mild to moderate chronic obstructive pulmonary disease (COPD) (C) immunostained for identification of Ku86+cells (brown). Results are representative of those from nine non-smokers, 13 smokers with normal lung function, 14 patients with mild/moderate COPD. (D) Western blotting analysis of Ku86 (with actin controls) in whole lung parenchyma lysates from one non-smoker (N), three healthy smokers with normal lung function $(S)$ and three patients with mild to moderate COPD (C). Histograms represent the mean (SD) of the Ku86/actin ratio in healthy smokers $(n=6)$ and patients with $\operatorname{COPD}(n=6)$.

\section{Immunohistochemistry for Ku70 and Ku86 in mouse lung parenchyma}

Using a smoke-exposed mouse model the authors were also able to demonstrate predominant nuclear Ku 70 and Ku86 localisation in bronchial epithelial cells (figure 5). The expression of Ku86 in the bronchial epithelial cells was decreased to a statistically significant extent only in susceptible A/J mice ( $p=0.012)$ but not in C57BL/6J mice $(p=0.44)$ exposed to cigarette smoke. This decrease was prevented by treatment of $\mathrm{A} / \mathrm{J}$ mice with $\mathrm{N}$-acetylcysteine (NAC), as determined by immunohistochemistry (A/J mice: median (interquartile range) $75 \%(71 \%-83 \%)$ for controls vs $66 \%(57 \%-$ $70 \%)$ for smoke-exposed mice vs $73 \%(67 \%-78 \%)$ for NAC + smoke-exposed mice; $\mathrm{p}=0.012$ for controls vs smoke-exposed mice; C57BL/6J: 75\% (68\%-88\%) for controls vs 71\% (65\%-83\%) for smoke-exposed mice; $\mathrm{p}=0.44$ ) (figure 5). In contrast, the expression of $\mathrm{Ku} 70$ in the bronchial epithelial cells was not statistically significantly different between controls and smokeexposed mice in either A/J or C57BL/6J strains (data not shown).

\section{Effect of $\mathrm{H}_{2} \mathrm{O}_{2}$ on $\mathrm{Ku} 70 / \mathrm{Ku} 86$ expression in primary human bronchial epithelial cells}

Stimulation of primary human bronchial epithelial cells with hydrogen peroxide in vitro produced a statistically significant reduction in Ku86 but not Ku70 expression ( $p<0.0112$; figure 6A,B). Additionally, knockdown of Ku86 protein in bronchial epithelial BEAS-2B cells using siRNA resulted in a statistically significant reduction of the ability of these cells to induce $\mathrm{AP}$ sites in response to $\mathrm{H}_{2} \mathrm{O}_{2}$ exposure (figure $6 \mathrm{C}-\mathrm{E}$ ).

\section{DISCUSSION}

There is a selective decrease in the level of the DNA repair protein Ku86 in the bronchiolar epithelium of patients with COPD. This has also been confirmed in the cigarette-smoke exposed murine strain susceptible to lung cancer. In vitro, the exposure of bronchial epithelial cells to $\mathrm{H}_{2} \mathrm{O}_{2}$ reproduced the selective pattern of Ku86 expression decrease observed in COPD. In addition, the study demonstrated for the first time that the number of AP sites is significantly increased in lung parenchyma from smokers with normal lung function compared with nonsmokers, whereas the level of $8-\mathrm{OH}-\mathrm{dG}$ is significantly increased in lung parenchyma from all smokers with or without COPD compared with non-smokers.

AP levels reflect both ongoing DNA damage and DNA repair of the damage. To the authors' surprise, this combined marker of DNA damage/repair was higher in smokers with normal lung function compared with smokers with COPD. In contrast, 8-OH-dG and $\gamma$-H2AFX, markers of DNA damage, were not significantly different between smokers with normal lung function and current and former smokers with COPD, reflecting similar levels of smoking exposure. The absence of increased AP levels in patients with COPD might be a consequence of a loss of DNA repair secondary to a lack of Ku86 in bronchiolar epithelial cells.

Furthermore, short-term (11 days) cigarette smoke exposure in mice decreased K86 expression in bronchial epithelial cells
Figure 3 Photomicrographs showing the bronchiolar epithelium from a nonsmoker $(A, D)$, a healthy smoker with normal lung function $(B, E)$ and a patient with mild to moderate chronic obstructive pulmonary disease (COPD) $(\mathrm{C}, \mathrm{F})$ immunostained brown for identification of Ku70+ (left panel) and DNA-PKcs+cells (right panel). Results are representative of those from nine non-smokers, 13 smokers with normal lung function and 14 patients with mild to moderate COPD. (G) Western blotting analysis of Ku70 (with actin controls) in whole lung parenchyma lysates from four healthy smokers with normal lung function (S) and four patients with mild to moderate COPD (C). Histograms represent the mean (SD) of the Ku70/actin ratio in healthy smokers $(n=6)$ and COPD $(n=6)$.
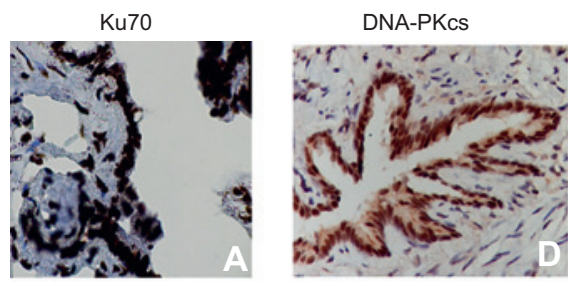

G
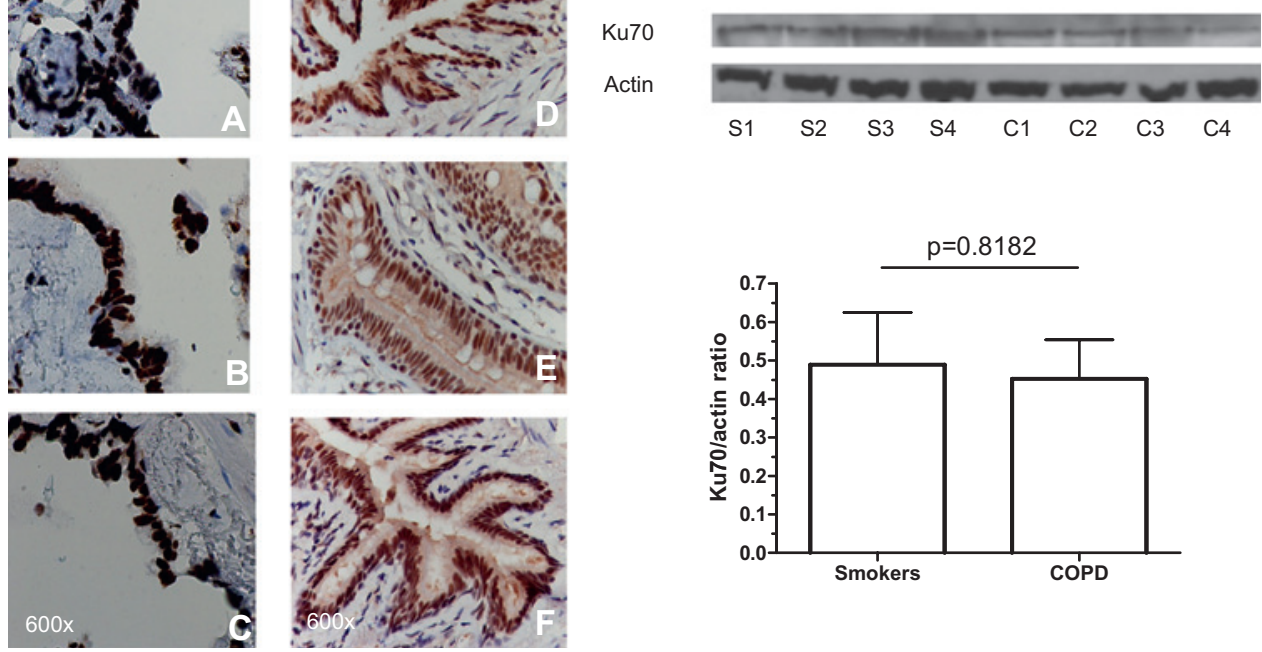
Figure 4 Photomicrographs showing the bronchial epithelium from a healthy smoker with normal lung function ( $A$, C) and a patient with mild to moderate chronic obstructive pulmonary disease (COPD) (B, D) immunostained for identification of $\gamma-\mathrm{H} 2 \mathrm{AFX}+(\mathrm{A}, \mathrm{B})$ and phospho-DNA-PKcs $+(C, D)$ cells (brown). Results are representative of those from 13 healthy smokers with normal lung function and 14 patients with mild to moderate COPD.

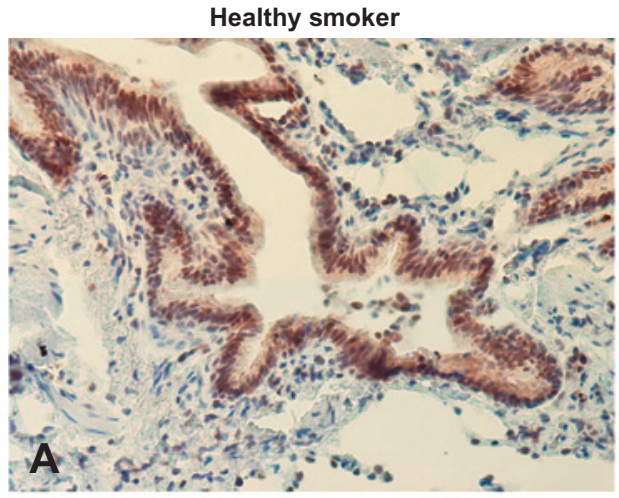

$\gamma$-H2AFX

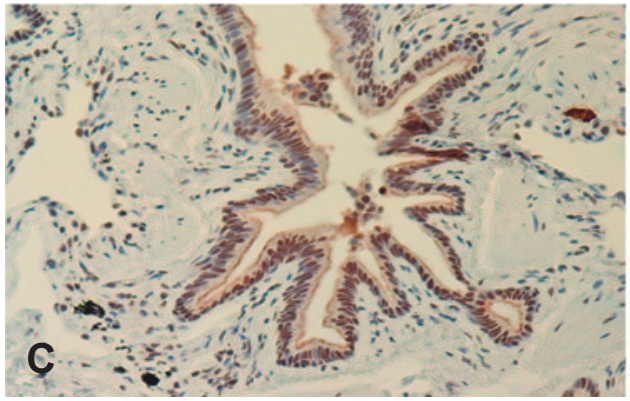

Phospho-DNA-PKcs

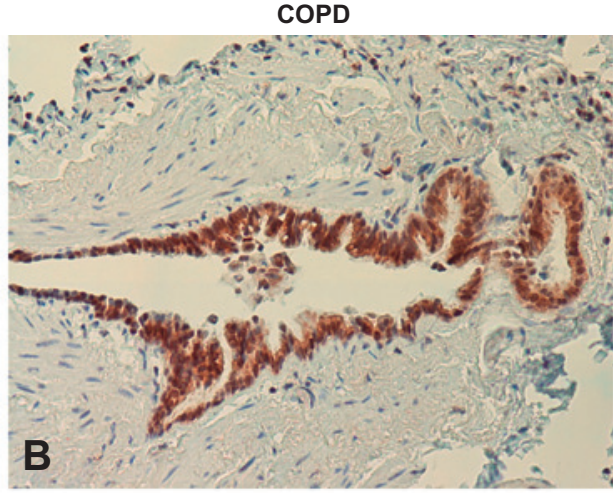

$\gamma$-H2AFX

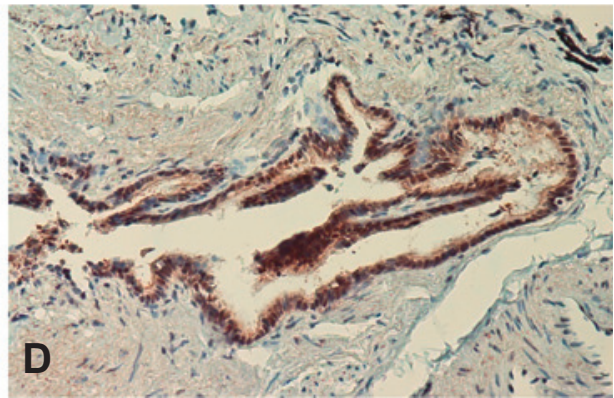

Phospho-DNA-PKcs only in the $\mathrm{A} / \mathrm{J}$ strains, susceptible to tobacco-smoke induced lung cancer, and this effect is prevented by the treatment with the antioxidant NAC. Finally, in vitro studies demonstrated that in bronchial epithelial cells $\mathrm{H}_{2} \mathrm{O}_{2}$ can decrease $\mathrm{Ku} 86$, but not $\mathrm{Ku} 70$, expression, and Ku86 knockdown demonstrates a significant modulation of AP levels by preventing restoration of levels to baseline.

A previous study demonstrated a reduction of DNA-PK activity in peripheral blood mononuclear cells (PBMCs) obtained from patients with non-small cell lung cancer (NSCLC) compared with those without lung cancer. ${ }^{18}$ The same study also demonstrated that the DNA-PK activity in PBMCs reflected that seen in bronchial epithelial cells. ${ }^{18}$ This reduced DNA-PK activity may be linked to the decreased Ku86 expression reported here. Several studies have already shown that despite leucocytes not being the direct target of tobacco carcinogens, the level of DNA damage in PBMCs correlates with tobacco smokinginduced DNA damage in human lung tissues. ${ }^{19} 20$ This is in keeping with the concept of COPD having a major systemic component. $^{21}$

The absence of significant differences in bronchiolar expression of phospho-DNA-PKcs in this study may suggest that
A

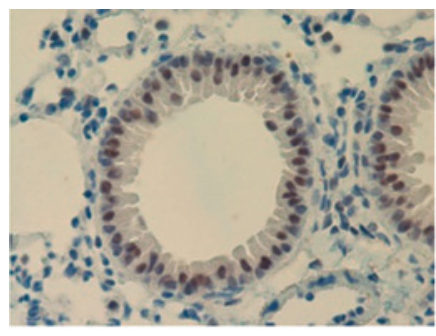

C57BL/6J control

B

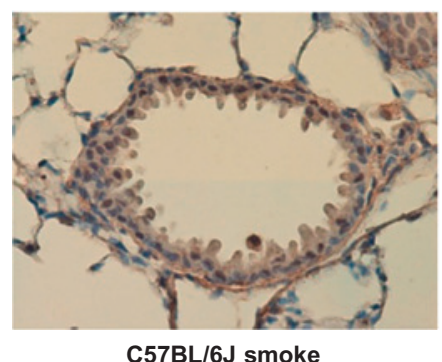

D

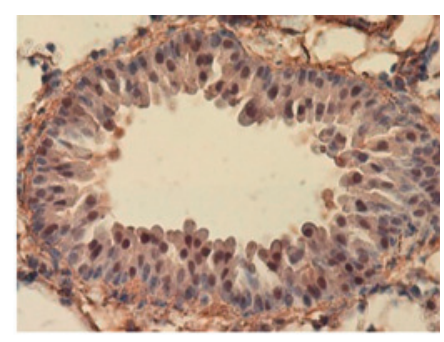

A/J control
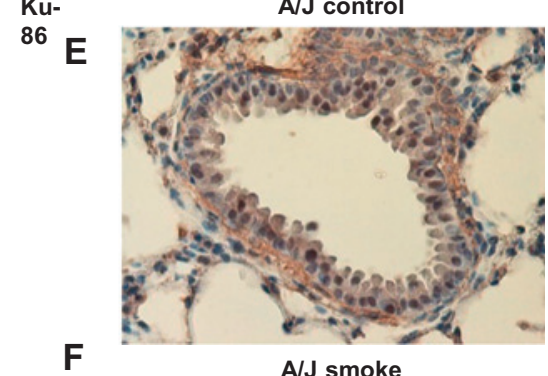

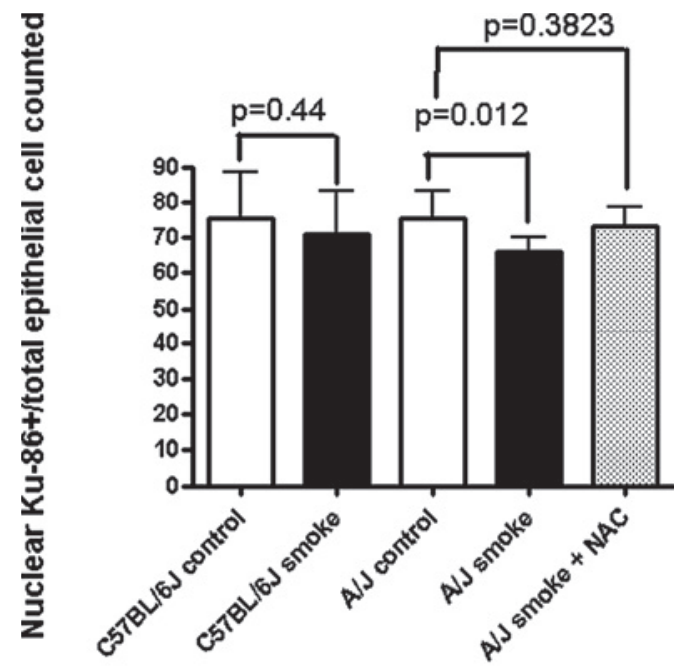

Mice strains and treatments

Figure 5 Photomicrographs showing the bronchial epithelium from a control $(A, D)$ and a cigarette-smoke exposed $(B, E)$ mouse respectively of the $\mathrm{C} 57 \mathrm{BL} / 6 \mathrm{~J}(\mathrm{~A}, \mathrm{~B})$ and $\mathrm{A} / \mathrm{J}(\mathrm{D}, \mathrm{E})$ strains immunostained for identification of Ku86 + cells (brown). Histograms represent the median (IQR) of the percentage of bronchial epithelial cells with nuclear immunostaining for Ku86 on total number of bronchial epithelial cells in controls ( $n=6$ and 8 for C57BL/6J and $\mathrm{A} / \mathrm{J}$ strains respectively) and cigarette-smoke exposed mice ( $n=7$ and 11 for $\mathrm{C} 57 \mathrm{BL} / 6 \mathrm{~J}$ and $\mathrm{A} / \mathrm{J}$ strains respectively) of $\mathrm{C} 57 \mathrm{BL} / 6 \mathrm{~J}(\mathrm{C})$ and $\mathrm{A} / \mathrm{J}(\mathrm{F})$ strains. 
Figure 6 Graphical representation of Ku86 (A) and Ku70 (B) expression, measured by immunoenzymatic analysis, in nuclear extracts from primary human bronchial epithelial cells before (control) and after stimulation with hydrogen peroxide $\left(\mathrm{H}_{2} \mathrm{O}_{2}\right)$. (C) Real time PCR analysis of Ku86 mRNA expression in lysates from wild type (Wt) and Ku86 knockdown (KD) BEAS-2B cells. (D) Western blotting analysis of Ku86 expression in lysates from Wt and KD BEAS-2B cells. (E) Effects of Ku86 knockdown in bronchial epithelial BEAS-2B cells using siRNA in the modulation of the ability of these cells to induce AP sites in response to hydrogen peroxide stimulation. Results are expressed as mean (SD) and are representative of three separate experiments. * $p$ compared with control cells at $\mathrm{t}=0 \mathrm{~h} ; \hat{\mathrm{p}}$ compared with Ku86 siRNA-treated cells at $\mathrm{t}=12 \mathrm{~h}$.
A
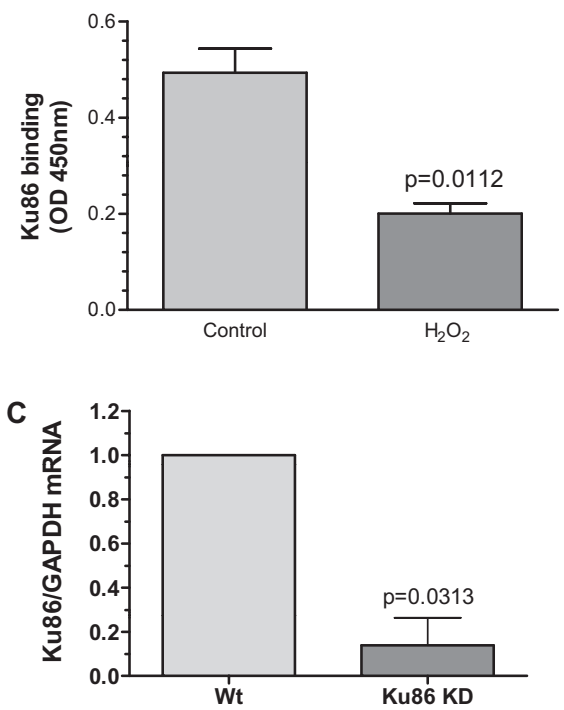

D

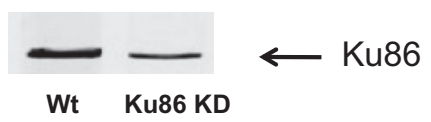

B
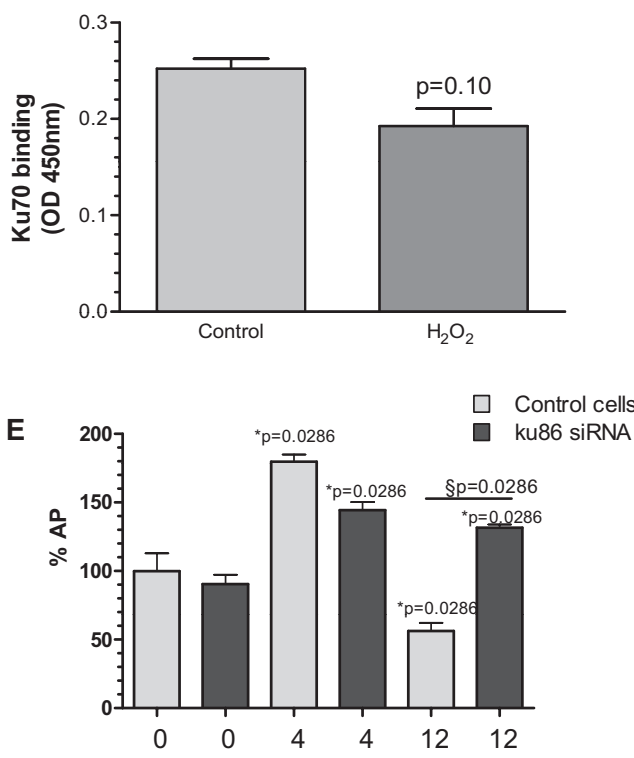

Time $\mathrm{H}_{2} \mathrm{O}_{2}(100 \mu \mathrm{M})$ exposure (hrs)
DNA-PKcs autophosphorylation, which in vitro correlates with loss of protein kinase activity and dissociation of the DNA-PKcs-Ku complex, ${ }^{9}$ may not be an important mechanism in COPD lungs.

COPD is an independent risk factor for lung carcinoma, particularly for squamous cell carcinoma, among smokers. ${ }^{4}$ It is also associated with increased oxidative stress which can cause DNA damage. ${ }^{6}$ Lung cancer is up to five times more likely to occur in smokers with airflow obstruction than those with normal lung function ${ }^{5}$ and lung cancer is one of the commonest causes of death among patients with COPD. ${ }^{22}$ The authors hypothesise that a defective DNA repair mechanism in smokers with COPD in response to oxidative stress will contribute to the increased incidence of lung carcinoma in these patients.

Recent evidence has determined a critical role for acetylation of histone $\mathrm{H3}$ on lysine 56 (AcH3K56) in DNA damage and repair. ${ }^{23}{ }^{24}$ Furthermore, deacetylation of AcH3K56 is controlled by histone deacetylases (HDACs) 1 and 2 and loss of HDAC1 and/or 2 can increase susceptibility to UVA irradiation. ${ }^{23}$ Further evidence for a role of HDAC-containing complexes in the regulation of DNA damage and repair is seen in Caenorhabditis elegans in response to ionising radiation ${ }^{25}$ and there also appears to be an important role for sirtuins in deacetylating H3K56 in mammalian cells. ${ }^{24} 26$ This suggests that in diseases such as COPD where there is a decrease in both HDAC2 $2^{27}$ and SIRT $1^{28}$ expression/activity in the lungs there will be less protection against DNA strand break and repair induced by environmental factors, increasing the potential for somatic mutations and increasing the risk of lung cancer.

Ku86-deficient mice have early senescence and mortality but do not show an increased incidence of lung cancer. ${ }^{29}$ However, the effects of long-term tobacco smoke exposure on these animals have not been investigated. Further studies using a conditional Ku86 knockout chronically exposed to tobacco smoke will aid the understanding of the role of decreased Ku86 in facilitating lung cancer.

In conclusion, these data suggest that a reduced expression of the DNA repair protein Ku86 in the nucleus of the bronchiolar epithelial cells from patients with COPD can contribute to their increased risk of developing lung carcinoma.

Funding The study was supported by grants from Fondazione Carife (Ferrara, Italy; http://www.fondazionecarife.it/) and Associazione per la Ricerca e la Cura dell'Asma (ARCA, Padova, Italy) and the Wellcome Trust.

\section{Competing interests None.}

Ethics approval This study was conducted with the approval of the Ethics committees of the University Hospital of Ferrara and the Royal Brompton Hospital.

Contributors GC, PJB, KFC and AP contributed to the recruitment of the human subjects of the study. GV and CC prepared the animal model. GC, PC, KI, EJ, LT performed the experiments of molecular biology. They were all blinded on the clinica characterisation of the human subjects and on the experimental conditions of the animal model. IMA analysed and interpreted the clinical and experimental data. GC and AP obtained funding. GC and IAM drafted the manuscript which was critically revised for important intellectual contents by all other authors.

Provenance and peer review Not commissioned; externally peer reviewed.

\section{REFERENCES}

1. Hoffman PC, Mauer AM, Vokes EE. Lung cancer. Lancet 2000;355:479-85. Erratum in: Lancet 2000;355:1280.

2. National Institutes of Health, National Heart, Lung and Blood Institute. Global Initiative for Chronic Obstructive Lung Disease (GOLD): global strategy for the diagnosis, management and prevention of chronic obstructive pulmonary disease, NHLBI/WHO workshop report. NIH Publication No 2701A. http://www.goldcopd. com/ (accessed 15 Feb 2011).

3. Papi A, Casoni G, Caramori G, et al. COPD increases the risk of squamous histological subtype in smokers who develop non-small cell lung carcinoma. Thorax 2004;59:679-81.

4. Caramori G, Casolari P, Cavallesco GN, et al. Mechanisms involved in lung cancer development in COPD. Int J Biochem Cell Biol. Published Online First: 14 October 2010. doi:10.1016/j.biocel.2010.08.022.

5. Young RP, Hopkins RJ. Link between COPD and lung cancer. Respir Med 2010;104:758-9.

6. Psarras S, Caramori G, Contoli M, et al. Oxidants in asthma and chronic obstructive pulmonary disease (COPD). Curr Pharm Des 2005:11:2053-62.

7. Sancar A, Lindsey-Boltz LA, Unsal-Kacmaz K, et al. Molecular mechanisms of mammalian DNA repair and the DNA damage checkpoints. Annu Rev Biochem 2004;73:39-85.

8. Meek K, Gupta S, Ramsden DA, et al. The DNA-dependent protein kinase: the director at the end. Immunol Rev 2004;200:132-41.

9. Meek K, Dang V, Lees-Miller SP. DNA-PK: the means to justify the ends? Adv Immunol 2008:99:33-58.

10. Downs JA, Jackson SP. A means to a DNA end: the many roles of Ku. Nat Rev Mol Cell Biol 2004;5:367-78. 
11. Song JY, Lim JW, Kim H, et al. Oxidative stress induces nuclear loss of DNA repair proteins Ku70 and Ku80 and apoptosis in pancreatic acinar AR42J cells. J Biol Chem 2003;278:36676-87.

12. Atamna H, Cheung I, Ames BN. A method for detecting abasic sites in living cells: age-dependent changes in base excision repair. Proc Natl Acad Sci U S A 2000;97:686-91.

13. Kasai H. Analysis of a form of oxidative DNA damage, 8-hydroxy-2'-deoxyguanosine, as a marker of cellular oxidative stress during carcinogenesis. Mutat Res 1997:387:147-63.

14. Deslee G, Woods JC, Moore C, et al. Oxidative damage to nucleic acids in severe emphysema. Chest 2009;135:965-74.

15. Kinner A, Wu W, Staudt C, et al. Gamma-H2AX in recognition and signaling of DNA double-strand breaks in the context of chromatin. Nucleic Acids Res 2008;36:5678-94.

16. Papi A, Romagnoli M, Baraldo S, et al. Partial reversibility of airflow limitation and increased exhaled NO and sputum eosinophilia in chronic obstructive pulmonary disease. Am J Respir Crit Care Med 2000:162:1773-7.

17. Quanjer PH, Tammeling GJ, Cotes JE, et al. Lung volumes and forced ventilatory flows. Report of Working Party, standardization of lung function tests, European Community for Steel and Coal, official statement of the European Respiratory Society. Eur Respir J Supp/ 1993;16:5-40.

18. Auckley DH, Crowell RE, Heaphy ER, et al. Reduced DNA-dependent protein kinase activity is associated with lung cancer. Carcinogenesis 2001:22:723-7.

19. Perera FP, Mooney LA, Stampfer M, et al; Physicians' Health Cohort Study. Associations between carcinogen-DNA damage, glutathione S-transferase genotypes, and risk of lung cancer in the prospective Physicians' Health Cohort Study. Carcinogenesis 2002;23:1641-6.
20. Wiencke JK, Kelsey KT, Varkonyi A, et al. Correlation of DNA adducts in blood mononuclear cells with tobacco carcinogen-induced damage in human lung. Cancer Res 1995:55:4910-14.

21. Fabbri LM, Rabe KF. From COPD to chronic systemic inflammatory syndrome? Lancet 2007;370:797-9.

22. Calverley PM, Anderson JA, Celli B, et al; TORCH investigators. Salmeterol and fluticasone propionate and survival in chronic obstructive pulmonary disease. N Eng J Med 2007;356:775-89.

23. Miller KM, Tjeertes JV, Coates J, et al. Human HDAC1 and HDAC2 function in the DNA-damage response to promote DNA nonhomologous end-joining. Nat Struct Mol Biol 2010;17:1144-51.

24. Vempati RK, Jayani RS, Notani D, et al. p300-mediated acetylation of histone H3 lysine 56 functions in DNA damage response in mammals. J Biol Chem 2010;285:28553-64.

25. Smeenk G, Wiegant WW, Vrolijk $\mathrm{H}$, et al. The NuRD chromatin-remodeling complex regulates signaling and repair of DNA damage. J Cell Biol 2010:190:741-9.

26. Yuan J, Pu M, Zhang Z, et al. Histone H3-K56 acetylation is important for genomic stability in mammals. Cell Cycle 2009;8:1747-53.

27. Ito $\mathbf{K}$, Ito $\mathrm{M}$, Elliott WM, et al. Decreased histone deacetylase activity in chronic obstructive pulmonary disease: relationship to disease severity. N Engl J Med 2005;352:1967-76

28. Rajendrasozhan S, Yang SR, Kinnula VL, et al. SIRT1, an antiinflammatory and antiaging protein, is decreased in lungs of patients with chronic obstructive pulmonary disease. Am J Respir Crit Care Med 2008;177:861-70.

29. Vogel H, Lim DS, Karsenty G, et al. Deletion of Ku86 causes early onset of senescence in mice. Proc Natl Acad Sci U S A 1999;96:10770-5.

\section{Advancing} Postgraduates. Enhancing Healthcare.

The Postgraduate Medical Journal is dedicated to advancing the understanding of postgraduate medical education and training.

- Acquire the necessary skills to deliver the highest possible standards of patient care

- Develop suitable training programmes for your trainees

- Maintain high standards after training ends

Published on behalf of the fellowship for Postgraduate Medicine
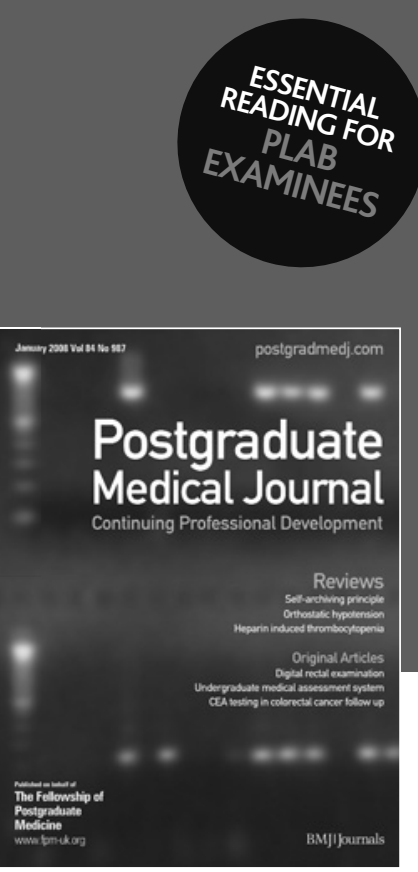

FOR MORE DETAILS OR TO SUBSCRIBE,

VISIT THE WEBSITE TODAY

BMJIJournals

\section{postgradmedj.com}

